\title{
Análise qualitativa dos efeitos da sonoforese com Arnica montana sobre o processo inflamatório agudo do músculo esquelético de ratos Qualitative analysis of effects of phonophoresis with Arnica montana onto acute inflammatory process in rat skeletal muscles
}

\author{
Patrícia Pereira Alfredol, Carlos Alberto Anaruma ${ }^{2}$, Antônio Carlos Simões Pião ${ }^{3}$, \\ Ślvia Maria Amado João ${ }^{4}$, Raquel Aparecida Casarotto ${ }^{4}$
}

Estudo desenvolvido no Programa de Pós-Graduação em Ciências da Reabilitação do Fofito/ FMUSP - Depto. de Fisioterapia, Fonoaudiologia e Terapia Ocupacional da Faculdade de Medicina da Universidade de São Paulo, São Paulo SP, Brasil

1 Fisioterapeuta Ms.; doutoranda no Programa de Pós-Graduação em FisioPatologia Experimental do Fofito/FMUSP

2 Prof. Dr. do Depto. de Educação Física, Instituto de Biociências, Unesp Universidade Estadual Paulista, Rio Claro, SP, Brasil

3 Prof. Dr. do Depto. de Estatística, Matemática Aplicada e Computacional da Unesp - Rio Claro

4 Profas. Dras. do Curso de Fisioterapia do Fofito/FMUSP

ENDEREÇO PARA CORRESPONDÊNCIA

Patrícia Pereira Alfredo R. Profa. Gioconda Mussolini 23 Edifício Felipe apto. 11 Jardim Risso

05587-120 São Paulo SP e-mail: patriciaalfredo@usp.br

APRESENTAÇÃO fev. 2008

ACEITO PARA PUBLICAÇÃO set. 2008
Resumo: Este estudo visou verificar o efeito da sonoforese com Arnica montana sobre a fase inflamatória aguda de uma lesão muscular. Para isso, 40 ratos Wistar machos, lesados cirurgicamente, foram divididos em 4 grupos: controle (C), 10 ratos lesados e não tratados; grupo ultra-som (US), 10 lesados, tratados com US; grupo ultra-som com arnica $(U S+A), 10$ ratos lesados, tratados com sonoforese de gel de arnica; grupo arnica (A), 10 ratos lesados, tratados com massagem de gel de arnica. O tratamento dos três grupos foi iniciado $24 \mathrm{~h}$ após a lesão, sendo aplicado uma vez ao dia durante 3 minutos, por três dias. Quatro dias após a lesão, os animais foram sacrificados e o terço médio do músculo tibial anterior lesado foi removido e tratado histologicamente. Os resultados da análise qualitativa mostram que, no grupo $C$, formou-se um intenso infiltrado de células inflamatórias no espaço intersticial e um processo de regeneração apenas iniciado. Nos grupos US e US+A foi detectado um avançado processo inflamatório, com tecido conjuntivo mais organizado e consistente. No grupo A foi detectada diminuição no número de células inflamatórias e uma desorganização em sua disposição, o que poderia levar a um atraso no processo de regeneração. Conclui-se que os grupos que receberam a aplicação do ultra-som e ultra-som com arnica apresentaram semelhante aceleração do processo inflamatório agudo, sugerindo ineficácia da sonoforese quando comparada à aplicação de apenas ultra-som.

Descritores: Arnica; Fonoforese; Músculo esquelético/anatomia \& histologia; Terapia por ultra-som

AвSTRACT: This study aimed at verifying the effects of phonophoresis associated to Arnica montana on the acute phase of an inflammatory muscle injury. Forty Wistar male rats of which the Tibialis Anterior muscle was surgically lesioned, were divided into 4 groups $(\mathrm{n}=10$ each): control group received no treatment; the ultrasound group (US), treated with US; the US+A group was treated with arnica phonophoresis; and the arnica group (A) received massage with arnica gel. Treatment for the three groups started $24 \mathrm{~h}$ after surgical injury and lasted 3 days, being applied during 3 minutes once a day. On the 4th day after lesion animals were sacrificed and sections of the injured, inflamed muscle were removed for histological analysis. Results showed, in C group, an intense infiltrate of inflammatory cells and an only incipient regeneration process; in both US and US+A groups an advanced inflammatory process was noticed, with organized and thick conjunctive tissue. In A group a reduced number of ill-arranged inflammatory cells was detected, which might lead to delays in the regeneration process. Since both US and US+A groups showed similar acceleration of the acute inflammatory process, it may be inferred that arnica phonophoresis did not have extra healing effect, hence is inneffective when compared to ultrasound alone.

Key words: Arnica; Muscle, skeletal/anatomy \& histology; Phonophoresis; Ultrasonic therapy 


\section{INTRODUÇÃO}

O músculo esquelético é um tecido sujeito a lesões em função das solicitações exigidas pelas atividades da vida diária e esportiva. A inflamação é um processo importante para a regeneração do tecido lesado, mas sua continuidade é sempre considerada indesejável ${ }^{1}$. A morbidade estrutural e funcional ocorre na forma de atrofia, contraturas, dor e aumento da probabilidade de se ter uma recidiva ${ }^{2}$.

A efetividade dos cuidados clínicos com tecidos estressados ou traumatizados depende de um bom entendimento dos eventos celulares e moleculares que levam a uma resposta fisiológica como a inflamação. A intervenção precoce pode oferecer estratégias benéficas para minimizar as alterações morfofuncionais após a lesão tecidual, facilitar o reparo e a recuperação da função.

O ultra-som terapêutico (US) é um recurso usado no tratamento de uma variedade de situações, incluindo aí a bioestimulação do reparo tecidual ${ }^{3-6}$, tendo um efeito de promover a cascata de cicatrização. De acordo com alguns autores ${ }^{7-9}$, o US pode facilitar a penetração de agentes antiinflamatórios aplicados topicamente sobre a pele - em uma técnica chamada de fonoforese ou sonoforese. A rota transdérmica de aplicação de agentes antiinflamatórios apresenta vantagens em relação à administração oral, pois, na aplicação tópica, a droga age diretamente sobre a área inflamada, evitando os riscos dos efeitos colaterais causados pelo metabolismo hepático e/ou sistêmico ${ }^{10}$.

No entanto, o transporte transdérmico de moléculas é limitado devido à baixa permeabilidade do extrato córneo da pele ${ }^{11}$. Embora o US o facilite, vários estudos têm mostrado que o aumento da permeabilidade do extrato córneo causado pelo US é mediado pela cavitação acústica. A cavitação instável seria responsável pelo aumento da permeabilidade da pele $^{12}$.

Alguns estudos constataram o efeito da sonoforese aumentando a penetração de pequenas moléculas através da pele $^{13}$, aplicando o US com freqüências terapêuticas (1 a $3 \mathrm{MHz}$ ). Porém, o aumento dos níveis do transporte de drogas através da pele foi observado somente com drogas específicas ${ }^{14}$. Devido à grande variação entre as drogas, ainda existem controvérsias sobre a eficácia da sonoforese em aumentar a penetração de drogas através da pele. Uma explicação para essa variação foi apresentada recentemente baseada nas diferenças das propriedades físico-químicas das drogas, por exemplo, lipofilicidade e peso molecular $^{14}$.

A Arnica montana é uma planta da família Asteraceae utilizada como medicamento homeopático. É usada topicamente para o tratamento de contusões, distensões musculares, alívio da dor e edema, cicatrizações, afecções bucais, entre outras ${ }^{15}$. Seus princípios ativos são lactonas sesquiterpênicas (arnicolide, helenalina e dihidrohelenalina), flavonóides (incluindo quercitina e seus derivados como quercitina3-mono-glucosídeo e quercitina-3glicogalacturônico), álcoois (arnidiol, arnilenediol, isoarnilenediol), carotenóides, óleo essencial, ácido fenilcarboxilico, entre outros ${ }^{16}$. As lactonas sesquiterpênicas, especialmente os ésteres helenalina e dihidro-helenalina, são os principais princípios ativos da Arnica montana, sendo responsáveis por sua atividade antiinflamatória, o que foi comprovado por vários estudos in vitro e in vivo ${ }^{15,17,18}$. Wagner et al. ${ }^{19}$ concluíram que uma quantidade suficiente de lactonas sesquiterpênicas penetra a barreira da pele, gerando efeitos antiinflamatórios.

O conhecimento da eficácia da aplicação via subcutânea de drogas antiinflamatórias, utilizando-se os efeitos da sonoforese, pode trazer informações importantes que auxiliariam na escolha da técnica na prática clínica. Como a arnica vem sendo utilizada topicamente de forma significativa em afecções do sistema musculoesquelético e nenhum estudo verificou seus efeitos com a sonoforese em lesões musculares, o objetivo deste trabalho foi avaliar a eficácia da sonoforese com Arnica montana na fase aguda da lesão muscular.
METODOLOGIA

Foram utilizados 40 ratos da linhagem Wistar, machos, sedentários, pesando em média 300 \pm 50 g, com 90 dias de vida. Esses animais foram obtidos no Biotério Central da UNESPBotucatu e mantidos no Biotério do Laboratório de Biodinâmica do Departamento de Educação Física do Instituto de Biociências da Unesp - Rio Claro, em gaiolas coletivas com no máximo cinco ratos, que foram alimentados com ração balanceada para roedores (Labina), com 23\% de proteína e água ad libitum, em condições ambientais controladas (12 horas de ciclo claro/escuro; ambiente higienizado; temperatura a $25^{\circ} \mathrm{C}$ e ventilação controlada).

Os ratos foram divididos aleatoriamente em quatro grupos $(n=10$ em cada): grupo controle (C) - sofreram lesão muscular, mas não foram submetidos a qualquer tratamento; grupo ultra-som (US) - sofreram lesão muscular e foram tratados com ultra-som; grupo sonoforese de arnica (US+A) sofreram lesão muscular e foram tratados com ultra-som e gel de arnica; e grupo arnica (A) - sofreram lesão muscular e foram tratados com massagem de gel de arnica.

O experimento foi aprovado pela Comissão de Ética do Hospital das Clínicas da Faculdade de Medicina da Universidade de São Paulo.

\section{Procedimentos}

Os animais foram anestesiados com pentobarbital sódico a $2 \%$, pesados e tricotomizados na pata posterior direita. A pele foi seccionada, o músculo tibial anterior (TA) e sua fáscia foram expostos. Nestes foi feito um corte de $3 \mathrm{~mm}$ de largura por $3 \mathrm{~mm}$ de profundidade com auxílio de uma lâmina de bisturi, de maneira a seccionar as fibras transversalmente no terço médio do músculo. Nessas condições, o diâmetro da área lesada foi considerado como de $0,5 \mathrm{~cm}^{2}$. Feita a lesão, a pele foi suturada e no local foi feita assepsia com álcool 70\%. Durante os dois primeiros dias, foram oferecidas 20 gotas de dipirona sódica diluída em meio litro de água para todos os animais. 
Neste experimento foi usado um aparelho gerador de ondas ultra-sônicas modelo Sonacel (da Bioset Indústria de Tecnologia Eletrônica Ltda.), tendo o cabeçote área de radiação efetiva de $0,5 \mathrm{~cm}^{2}$. Antes de ser utilizado, o aparelho foi calibrado em uma balança radiométrica Ultrasound Power Meter com precisão de $\pm 20 \mathrm{~mW}$. A área do transdutor foi de $1 \mathrm{~cm}^{2}$ e o tipo de cristal gerador de ultra-som foi a cerâmica PZT. A fim de excluir o ar entre as interfaces, evitando assim a reflexão da onda ultra-sônica ${ }^{21}$, foram utilizados como agentes acopladores 500 mg de gel hidrossolúvel comercial ou gel de arnica, dependendo do grupo.

O gel de arnica utilizado é comercializado pelo Herbarium Laboratório Botânico Ltda., preparado com tintura de Arnica montana. A dosagem utilizada foi a recomendada pela Anvisa - Agência Nacional de Vigilância Sanitária ${ }^{20}$, que preconiza a aplicação tópica de uma dose diária de $1 \mathrm{mg} / \mathrm{ml}$ de lactonas sesquiterpênicas. Cada grama do gel de arnica contém 200 mg de tintura. Considerando a composição do gel, foram aplicados em cada sessão 500 mg do gel.

Os animais dos grupos submetidos ao US foram tratados 24 horas após a cirurgia, com os seguintes parâmetros: freqüência de $1 \mathrm{MHz}$, intensidade de $0,5 \mathrm{w} / \mathrm{cm}^{2}$ (média temporal e espacial), modo pulsado 1:2 (2 ms on e 4 ms off, $50 \%)$, com cada sessão de aplicação tendo 3 minutos. No grupo arnica, foram aplicados $500 \mathrm{mg}$ de gel de arnica em massagem sobre a área lesada durante 3 minutos. Para a aplicação do US e da arnica, todos os animais foram anestesiados com pentobarbital sódico a 2\%. A aplicação foi feita uma vez ao dia, durante três dias. Os animais foram sacrificados 24 horas após a última aplicação.

Os animais foram submetidos à eutanásia no $4^{\circ}$ dia após a lesão com dose letal de 20mg/100g de pentobarbital sódico. O músculo TA dos diferentes grupos experimentais foi removido e seu terço médio, local da lesão, colhido e colocado em um suporte de cortiça com a ajuda de um meio de inclusão para congelamento (Tissue Tec). Após esta etapa, foi envolvido em talco mineral para ser criofixado em nitrogênio líquido, onde foi mantido e conservado. Os músculos foram congelados em uma posição onde os cortes puderam oferecer imagens transversais e longitudinais das fibras musculares e da fenda incisional.

Para análise morfológica das fibras musculares e do tecido conjuntivo adjacente, foram realizados cortes seriados com a espessura de $10 \mu \mathrm{m}$, obtidos em um criótomo (Criostato) a $-25^{\circ}$ C. Colheram-se uma série de amostras da região superficial da lesão e, a partir daí, mais duas séries localizadas a $200 \mu \mathrm{m}$ de profundidade da outra. Cada série de corte forneceu três lâminas, que foram coradas com H/ E (hematoxilina-eosina). Foi feita a documentação fotográfica das lâminas em fotomicroscópio Zeiss, para registrar as alterações morfofuncionais da lesão.

Foi feita análise qualitativa de 10 campos por amostra, totalizando 100 campos por grupo experimental.

\section{RESULTADOS}

A análise histológica das lâminas mostrou que o interior da fenda incisional produzida pela lesão cirúrgica e o tecido intersticial ou conectivo, próximo dos segmentos seccionados, estavam preenchidos por uma delicada rede de fibrina e por um rico infiltrado de células inflamatórias.

No grupo controle, as extremidades das fibras musculares seccionadas e com morfologia comprometida apresentaram núcleo centralizado e grupamentos de células fagocíticas em atividade (Figura 1C). Na borda da lesão, um infiltrado de células inflamatórias apresentou-se intenso, chegando a atingir todo o espaço intersticial dessas fibras musculares (Figura $3 \mathrm{C}$ ); no interior, surgiu uma fina rede de fibrina (Figura 2C). Pôde-se observar também inúmeras células fusiformes indiferenciadas, sugestivas de serem células satélites e fibroblastos em proliferação (Figura 4C).

Nas lâminas do grupo ultra-som, o tecido conjuntivo mostrou-se mais organizado e consistente, sendo que a fenda da lesão, diferente do grupo controle, apresentava pequenos vasos sangüíneos entre as fibras que inicia- ram sua regeneração e entre fragmentos necróticos das fibras em estado de degeneração (Figura 3US). Próximo à borda da lesão havia células fusiformes em proliferação, sugerindo o início da formação e diferenciação das células satélites em mioblastos (Figura 4US). Nesse grupo pôde ser notada maior espessura da rede de fibrina (Figura $2 \cup S)$, quando comparada à do grupo controle, e a presença de células gigantes multinucleadas (Figura 1US), que sugere a ocorrência intensa de fagocitose, acelerando o processo inflamatório.

No músculo dos animais do grupo sonoforese de arnica (ultra-som com arnica, US+A), o tecido conjuntivo recém-formado na fenda incisional apresentou-se preenchido por infiltrado inflamatório (Figura $1 \cup S+A)$. Os leucócitos aderidos à espessa rede de fibrina já estavam picnóticos, com sua atividade fagocítica esgotada, mostrando estado relativamente avançado de degeneração (Figura $2 \cup \mathrm{U}+\mathrm{A}$ ). $\mathrm{Na}$ região próxima à fenda incisional nota-se a presença de infiltrado inflamatório composto predominantemente por células polimorfonucleares do tipo neutrófilo (Figura $3 \cup S+A$ ) e, na matriz do tecido conjuntivo, por células mononucleadas como macrófagos, plasmócitos, mastócitos e fibroblastos (Figura $4 \cup S+A)$.

No grupo Arnica, além de algumas células polimorfonucleares e mononucleares (Figuras 1A e 3A), surgiram fibroblastos aderidos à rede de fibrina (Figuras 1A e 2A) bem como leitos vasculares, o que não se repetiu nos outros grupos. Esses são espaços sem formação de células endoteliais, por onde passa o sangue durante a fase de reparo. Na região onde as fibras musculares foram seccionadas, os fragmentos necróticos foram tomados por numerosos leucócitos, como neutrófilos e macrófagos em atividade fagocitária. No delicado tecido conjuntivo que começou a se formar notase que células inflamatórias, fibroblastos e células satélites estavam distribuídas de maneira desordenada (Figura 4A), o que poderia dificultar a organização dos mioblastos no sentido longitudinal do eixo das fibras, atrasando ou prejudicando a formação de miotubos. 

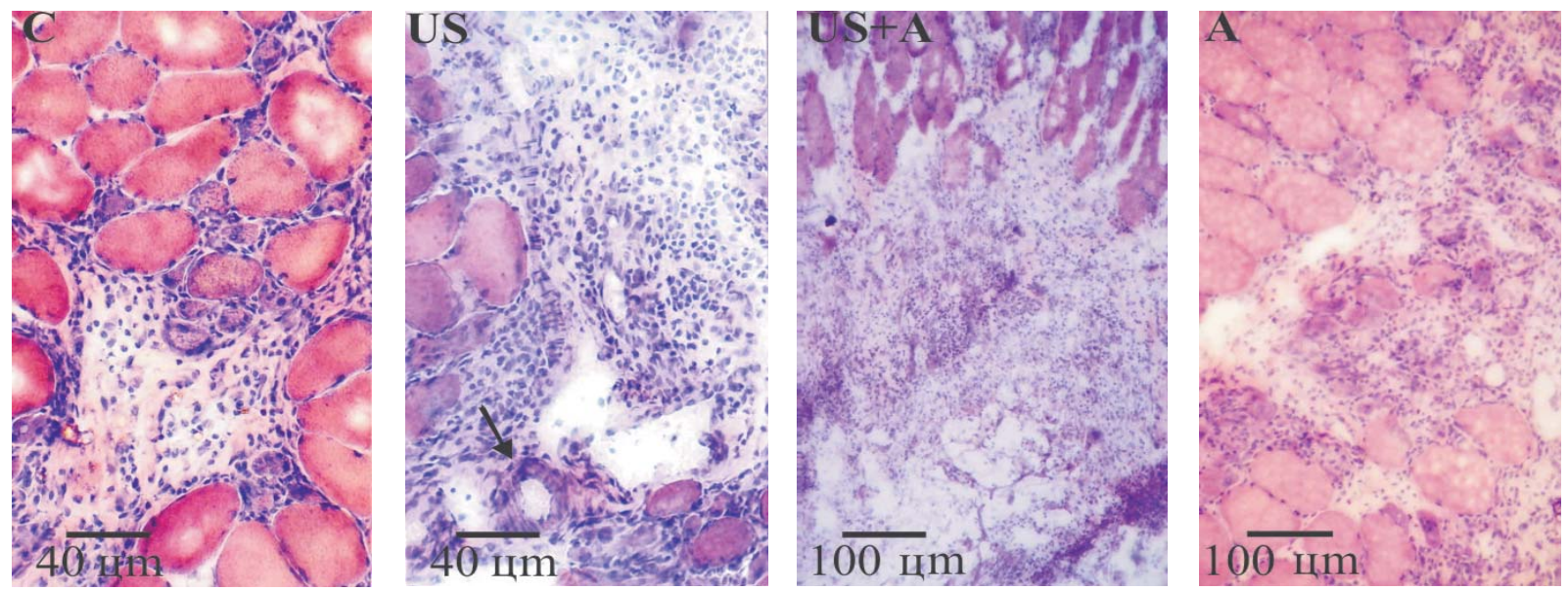

Figura 1 Fotomicrografia de músculo tibial anterior de rato dos grupos controle (C), ultra-som (US), sonoforese de arnica $(U S+A)$ e arnica $(A)$ : aspectos gerais

C: fibra muscular lesada com núcleos centralizados; US: células gigantes multinucleadas; US+A: infiltrado inflamatório em meio ao tecido necrótico; A: fibroblastos (seta grossa) entre células polimorfonucleares (seta curta) e mononucleares (seta fina)
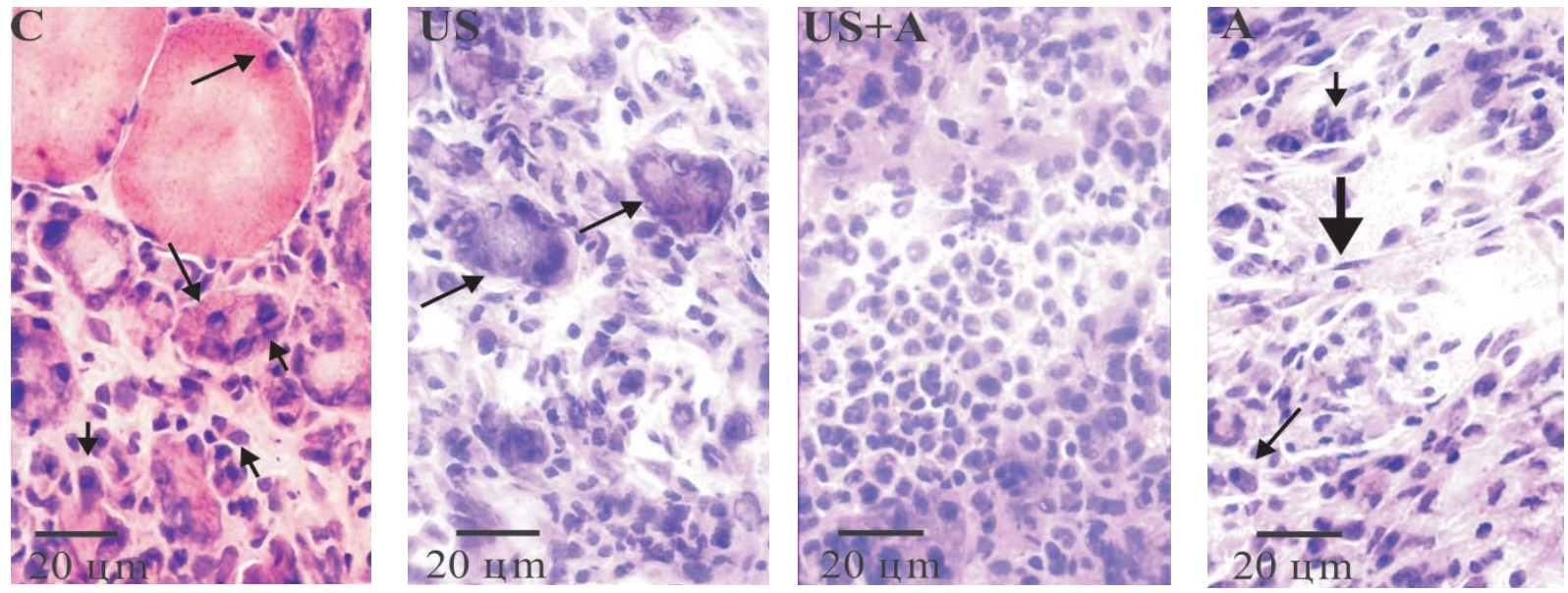

Figura 2 Fotomicrografia de músculo tibial anterior de rato dos grupos controle (C), ultra-som (US), sonoforese de arnica (US+A) e arnica (A): rede de fibrina

US+A: rede de fibrina com leucócitos picnóticos
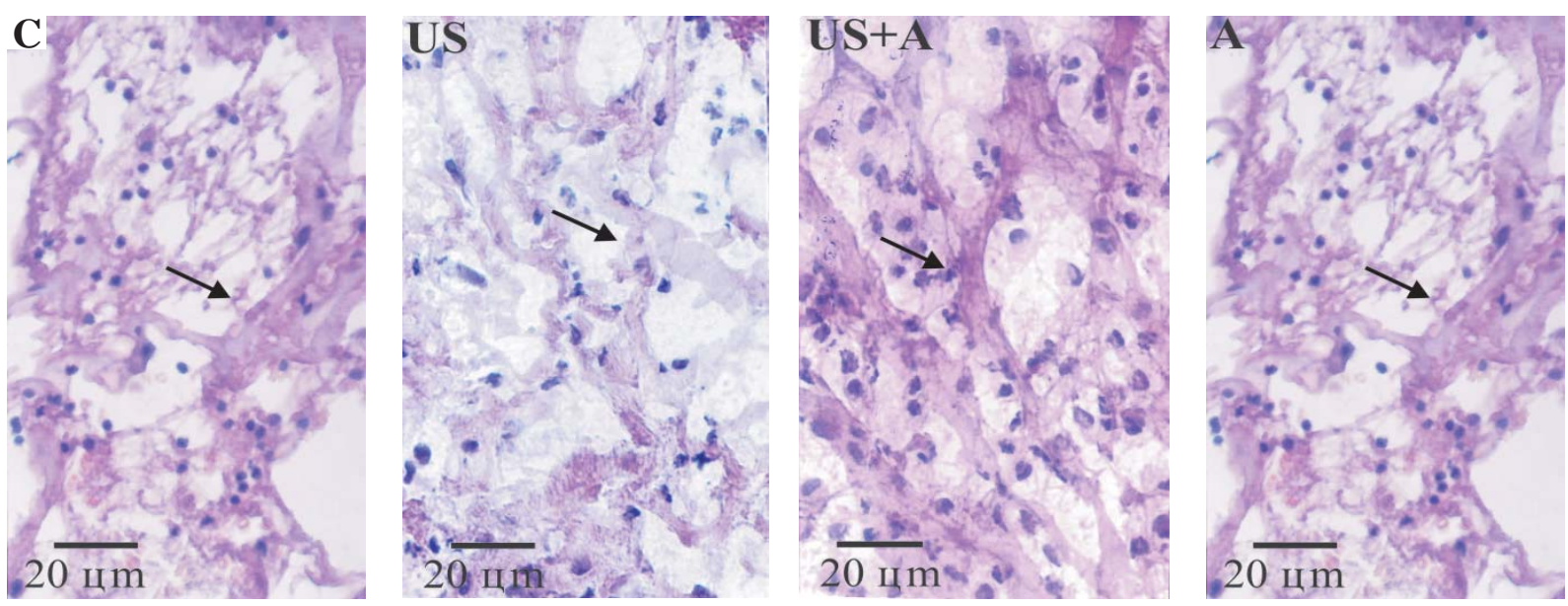

Figura 3 Fotomicrografia de músculo tibial anterior de rato dos grupos controle (C), ultra-som (US), sonoforese de arnica (US+A) e arnica (A): infiltrado inflamatório C: intenso; US: fibras em necrose com presença de vaso muscular 

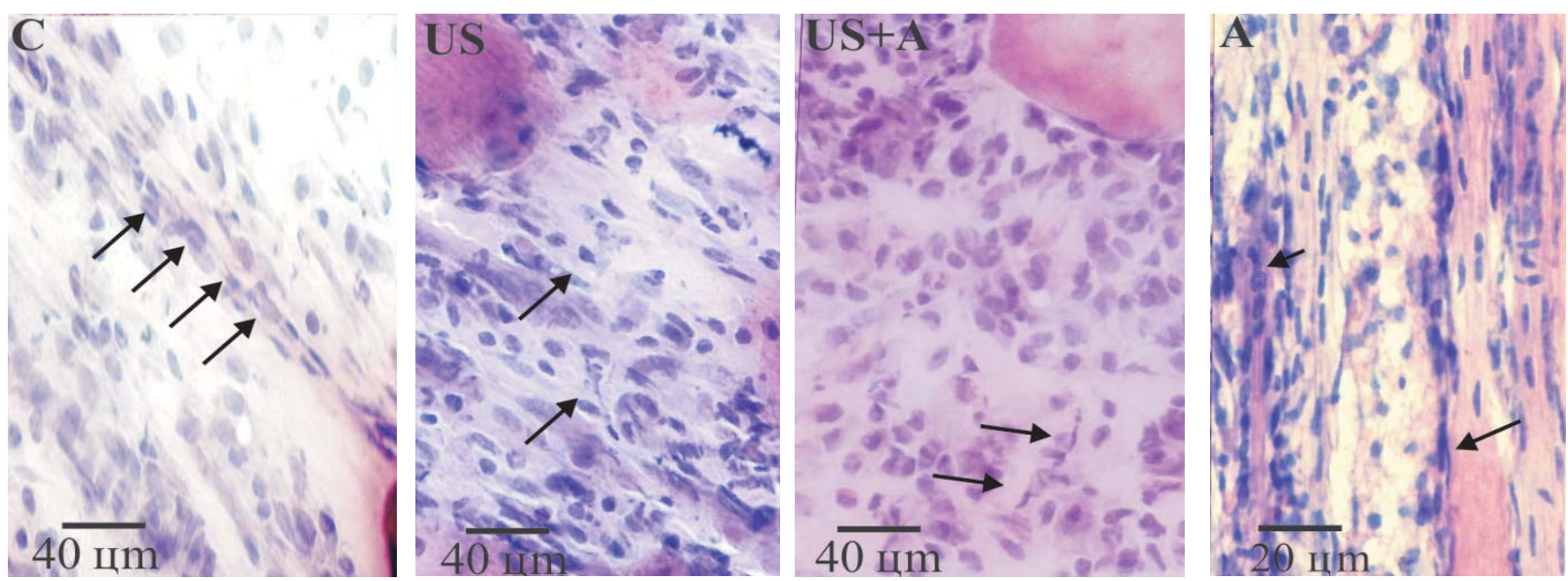

Figura 4 Fotomicrografia de músculo tibial anterior de rato dos grupos controle (C), ultra-som (US), sonoforese de arnica $(U S+A)$ e $\operatorname{arnica}(A)$ : processo de regeneração

C: células fusiformes indiferenciadas; US: células fusiformes em proliferação; US+A: fibroblastos; A: fibroblastos (seta fina) e células satélites (seta curta) distribuídas desordenadamente

\section{DISCUSSÃO E CONCLUSÃO}

Como os neutrófilos e macrófagos são as principais células de um processo inflamatório agudo ${ }^{22-25}$, decidiuse verificar neste estudo sua presença após os tratamentos recebidos.

Devido ao fato de o aumento da permeabilidade do extrato córneo da epiderme ser causado pelo efeito não-térmico de cavitação do US, foi escolhida a modalidade de aplicação pulsada. Love e Kremkau ${ }^{26}$ mostraram que o tratamento com US pulsado poderia causar um aumento menor do que 0,5 ${ }^{\circ} \mathrm{C}$ com 10 minutos de exposição.

Foi escolhida a freqüência terapêutica do transdutor de $1 \mathrm{MHz}$, para que pudesse alcançar o tecido muscular. A intensidade aplicada foi de $0,5 \mathrm{w} / \mathrm{cm}^{2}$, baseada nos resultados obtidos e analisados por Enwemeka et al. ${ }^{27}$ (1990), Gan et al. ${ }^{28}$ e Cunha et al..$^{5}$, que apóiam o uso de intensidades de $0,5 \mathrm{w} / \mathrm{cm}^{2}$ ou menores para obter taxas máximas de regeneração em tecidos.

O tratamento foi iniciado $24 \mathrm{~h}$ após a lesão para maximizar o efeito de regeneração do tratamento com o US pois, segundo Markert et al..$^{29}$ o início do tratamento antes das primeiras $24 \mathrm{~h}$ poderia levar ao aumento da ação degenerativa dos neutrófilos.

Observou-se neste estudo que o grupo controle, 96 h após a lesão mus- cular, apresentou um infiltrado inflamatório intenso entre as fibras musculares seccionadas (Figura 3C), sendo também observada a presença de células fusiformes sugestivas de serem células satélites e fibroblastos em proliferação (Figura 4C). Esse achado é semelhante ao de Hawake e Garry ${ }^{24}$, segundo os quais as células satélites começam a se diferenciar em mioblastos e miotúbulos 96 h após uma lesão.

O grupo ultra-som apresentou uma quantidade maior de células inflamatórias no sítio da lesão quando comparado ao grupo controle. Esses dados corroboram os de Speed $^{30}$, Kitchen e Partridge $^{31}$, mostrando a capacidade de o US acelerar as fases da inflamação, fazendo com que a fase de reparo seja adiantada em relação ao controle. A análise do padrão histológico revela que o tecido conjuntivo começou a se organizar com mais consistência e a rede de fibrina apresentou-se mais espessa, porém em menor extensão (Figura 2US). A presença de células gigantes multinucleadas, que nada mais são do que macrófagos fundidos (Figura 1US), demonstra a intensa atividade fagocítica na região. Nessa etapa, iniciou a regeneração das fibras lesadas (Figura 3US) com o conseqüente aumento da presença de células satélites. Esse fato pode ser um indicativo de aumento na velocidade de formação e diferenciação dos mioblastos (Figura 4US). Esses dados não foram observados no grupo controle.

No grupo arnica, verificou-se um menor número de neutrófilos no sítio da lesão, quando comparado ao grupo controle. Isso pode ser justificado pela ação antiinflamatória dos princípios ativos da arnica, a helenalina e dihidrohelenanina. Estas inibem o fator de transcrição NF-kB que regula a transcrição de várias citocinas inflamatórias, inibindo assim a migração e quimiotaxia de neutrófilos e, em grande dose, a síntese de prostaglandinas ${ }^{32,33}$. Sabese que a atuação de um antiinflamatório por um período prolongado de tempo pode levar a um atraso na recuperação e perda funcional em animais lesados ${ }^{34}$. O grupo arnica apresentou características histológicas que sugerem a possibilidade de haver um atraso no reparo tecidual, tais como a distribuição desordenada de células inflamatórias, fibroblastos e células satélites, que podem dificultar a organização dos mioblastos no sentido longitudinal das fibras e atrasar a formação dos miotubos, que raramente foram encontrados nesse grupo (Figura 4A).

O grupo ultra-som+arnica não apresentou diferenças morfológicas quando comparado ao grupo ultra-som: em ambos apresentou-se o mesmo efeito pró-inflamatório, acelerando a chegada das células inflamatórias ao local da lesão; em ambos, a rede de fibrina apresentou-se mais espessa; os leucócitos encontravam-se em avançado 
estado de degeneração ou picnóticos, o que aponta para uma eventual aceleração do processo de regeneração. Esses achados apontam para a ineficácia da sonoforese com arnica, na medida em que a similaridade dos resultados entre sonoforese e apenas ultra-som mostra que o gel de arnica aplicado com ultra-som não produziu nenhum efeito antiinflamatório a mais.
Por outro lado, o grupo que recebeu a aplicação tópica de arnica apresentou uma diminuição na chegada de neutrófilos, que são células importantes no processo inflamatório, além de uma desorganizada distribuição das células envolvidas nesse processo, o que poderia causar um atraso na regeneração tecidual.
Com base nesses achados, pode-se concluir que os grupos que receberam aplicação do ultra-som e de ultra-som com arnica apresentaram um similar estado avançado de regeneração do tecido lesado, com aceleração do processo inflamatório agudo, sugerindo ineficácia da sonoforese quando comparada à aplicação de apenas ultra-som.

\section{REFERÊNCIAS}

1 Worrell TW. Factors associated with hamstring injuries: an approach to treatment and preventive measures. Sports Med. 1994;17:338-45.

2 Kasemkijwattana C, Menetrey J, Somogyl G, Moreland MS, Fu FH, Buranapanitkit B, et al. Development of approaches to improve the healing following muscle contusion. Cell Transplant. 1998;7(6):585-98.

3 Dyson M, Pond JB, Josefh J, Warwick R. The stimulation of tissue regeneration by means of ultrasound. Clin Sci. 1968;35:273-85.

4 Dyson M, Suckling J. Stimulation of tissue repair by ultrasound: a survey of the mechanisms involved. Physiotherapy. 1978,64:105-8.

5 Cunha A, Parizotto NA, Vidal BC. The effect of therapeutic ultrasound on repair of the achilles tendon (tendo calcaneus) of the rat. Ultrasound Med Biol. 2001;27:1691-6.

6 Koeke PU, Parizotto NA, Carrinho PM, Solate ACB. Comparative study of the efficacy of the topical application of hydrocortisone, therapeutic ultrasound and phonophoresis on the tissue repair process in rat tendons. Ultrasound Med Biol. 2005;31:345-50.

7 Ueda H, Ogihara M, Sugibayashi K, Morimoto Y. Change in the eletrochemical properties of skin and lipid packing in stratum corneum by ultrasonic irradiation. Int J Pharm. 1996;137:217-24.

8 Fang JY, Fang CL, Sung KC, Chen HY. Effect of low frequency ultrasound on the vitro percutaneous absortion of clobetasol 17-proprionate. Int J Pharm. 1999;9:33-42.

9 Miller MW. Gene transfection and drug delivery. Ultrasound Med Biol. 2000;26:59-62.

10 Muller M, Mascher H, Kikuta C, Chafer S, Brunner $M$, Dorner $G$, et al. Diclofenac concentrations in defined tissue layers after topical administration. Clin Pharmacol Ther. 1997;62:293-9.
11 Mitragotri S. Synergistic effect of enhancers for transdermal drug delivery. Pharm Res. 2000;17(11):1354-9.

12 Tezel A, Mitragotri S. Interaction of inertial cavitation bubbles with stratum corneum lipid bilayers during low-frequency sonophoresis. J Biophys. 2003;85:3502-12.

13 Mitragotri S, Kost J. Low-frequency sonophoresis: a review. Adv Drug Deliv Rev. 2004;56:589-601.

14 Mitragotri S, Blankschtein D, Langer R. An explication for the variation of the sonophoretic transdermal transport enhancement from drug to drug. J Pharm Sci. 1997;86: 1190-92.

15 Knussel O, Weber M, Suter A. Arnica Montana gel in osteoarthritis of the knee: an open multicenter clinical trial. Adv Ther. 2002;19:209-18.

16- Bucay JW. Algumas notas sobre la planta medicinal Arnica montana. Rev Med Inst Mex Seguro Soc. 1995;33:312-26.

17 Klaas CA, Wagner G, Laufer S, Sosa S, Loggia RD, Bomme $U$, et al. Studies on the anti-inflamatory activity of phytopharmaceuticals prepared from arnica flowers. Planta Med. 2002;68:385-91.

18 Bergonzi MC, Bilia AR, Casiraghi A, Cilurzo F, Minghetti $\mathrm{P}$, Montanari $\mathrm{L}$, et al. Evaluation of skin permeability of sesquiterpenes of an innovative supercritical carbon dioxide arnica extract by HPLC/ DAD/MS. Pharmazie. 2005;60:36-8.

19 Wagner S, Suter A, Merfort I. Skin penetration studies of arnica preparations and of their sesquiterpene lactones. Planta Med. 2004;70:897-903.

20 Anvisa - Agência Nacional de Vigilância Sanitária. Legislação em Vigilância Sanitária. Resolução n 89, de 16 mar. 2004: Lista de registro simplificado de fitoterápicos. Diário Oficial da União, DF, 18 mar. 2004 [citado 8 fev. 2005]. Disponível em: http:// www.anvisa.gov.br. 
21 Casarotto RA, Adamowski JC, Fallopa F, Bacanelli F. Coupling agents in therapeutic ultrasound: acoustic and thermal behavior. Arch Phys Med Rehabil. 2004;85:162-5.

22 Grounds MD. Phagocytosis of necrotic muscle in muscle isografts is influenced by the straim, age, and sex of host mice. J Pathol. 1987;153:71-82.

23 Armstrong RB. Initial events in exercise-induced muscular injury. Med Sci Sports Exerc. 1990;22:429-35.

24 Hawke TJ, Garry DJ. Myogenic satellite cells: physiology to molecular biology. J Appl Physiol. 2001;91:534-51.

25 Pizza FX, Koh TJ, McGregor SJ, Brooks SV. Muscle inflammatory cells after passive stretches, isometric contractions, and lengthening contractions. J Appl Physiol. 2002;92:1873-8.

26 Love LA, Kremkau FW. Intracellular temperature distribution produced by ultrasound. J Accoust Soc Am. 1980;67:1045-50.

27 Enwemeka CS, Rodriguez O, Mendonza S. The biomechanical effects of low-intensity ultrasound on healing tendons. Ultrasound Med Biol. 1990;16:801-7.
28 Gan BS, Sherebrin MH, Scilley CG. The effects of ultrasound treatment on flexor tendon healing in the chicken limb. J Hand Surg. 1995;20:809-14.

29 Markert CD, Merrick MA, Kirby TE, Devor ST. Nonthermal ultrasound and exercise in skeletal muscle regeneration. Arch Phys Med Rehabil. 2005;86:1304-10.

30 Speed CA. Therapeutic ultrasound in soft tissue lesions. Rheumatology. 2001;40:1331-6.

31 Kitchen SS, Partridge CJ. A review of therapeutic ultrasound, part 1: background and physiological effects. Physiotherapy. 1990;76:593-5.

32 Hall IH, Starnes CO, Lee KH, Waddell TG. Mode of action of sesquiterpene lactones as anti-inflammatory agents. J Pharm Sci. 1980;69:537-43.

33 Tak PP, Firestein GS. NF-kB: a key role in inflammatory diseases. J Clin Invest. 2001;107:7-11.

34 Toumi H, Best TM. The inflammatory response: friend or enemy for muscle injury? Br J Sports Med. 2003;27:363-70. 